\title{
DISASTER MANAGEMENT AND ROLE OF ACADEMIC INSTITUTIONS IN NEPAL: CURRENT STATUS AND WAY FORWARD
}

\author{
Ramesh Raj Pant ${ }^{1}$, Kiran Bishwakarma ${ }^{2}$, Archana Ghimire ${ }^{3}$, Kripa Shrestha ${ }^{1}$, Rejina \\ Maskey ${ }^{1}$, Buddhi Raj Joshi ${ }^{4}$, Arjun Gautam ${ }^{4}$, and Madan Koirala ${ }^{1 *}$ \\ ${ }^{1}$ Central Department of Environmental Science, Institute of Science and Technology, Tribhuvan University, Nepal \\ ${ }^{2}$ Institute of Tibetan Plateau Research, Chinese Academy of Sciences, Beijing 100101, China \\ ${ }^{3}$ Research Center for Eco-Environmental Sciences, Chinese Academy of Sciences, Beijing, 100085, China \\ ${ }^{4}$ School of Engineering, Pokhara University, Kaski, Nepal \\ *For Correspondence: mkoirala@cdes.edu.np
}

\begin{abstract}
The intense natural disasters have been causing the great loss of life and properties in Nepal. This study attempts to figure out the status and role of Nepalese academia for the contribution of disaster risk reduction and management (DRRM). The methodology adopted for the study is reviewing the literature, policies, and academic documents including university curricula. The study highlighted that the constitution of Nepal 2015 and DRRM Act 2017 have provided ample opportunities via several legal provisions for federal, provincial, and local government to make their own modalities for making a disasterresilient society. The universities and higher academic institutions are responsible for sound knowledge-based research activities to address the issues of DRRM which could be directly adopted by different levels of governments in terms of their plans, policies, and programs. In this connection, attempts are being made by governments and academic institutions to develop disaster resilient communities by shifting the traditional way of just responding during disaster focusing on the disaster cycle. Precisely, ten major universities of Nepal have incorporated disaster components including preparedness, response, recovery, and mitigation-related academic curricula in their undergraduate and graduate levels academic programs. Introducing the Environmental Health in Disaster, and Public Health and Disaster Engineering in Tribhuvan University and Pokhara University, respectively is one of the good initiatives taken by the academia. However, there is still room for improvement in terms of the integration of DRRM courses in the curricula of higher academic institutions for making disaster-resilient communities.
\end{abstract}

Key words: Academia, DRRM, TU, PU, EHD, PHED

\section{INTRODUCTION}

The ever-increasing disasters are one of the global challenges in the $21^{\text {st }}$ century. A disaster is a disruption of the function involving the loss of life, disease, and negative effects on environmental and economic conditions (Tuladhar et. al.., 2014). There are several initiatives to minimize the impacts of disasters where disaster risk reduction and management
(DRRM) is one of the major approaches. It is a systematic process of using administrative directives, organizations, operational skills, and capacities to implement strategies, policies, and improved coping capacities in order to lessen the adverse impacts of hazards and the possibility of disaster (MoHA, 2019). In order to apply the concept and approaches of DRRM, the higher education institutions could play a 
crucial role in the task of embedding people's awareness on how to prevent, cope and recover from disasters. Also, they can identify their role to detect potential hazards and engage in research and sustainable management of disaster events. Furthermore, these institutions play a key role to formulate appropriate disaster reduction risk strategies by enabling societies to become engaged in the adoption of environment-friendly, conscious risk reduction and management techniques (Tuladhar et. al.., 2015). The DRRM requires the multidisciplinary knowledge that is also highlighted in Hyogo Framework for Action (HFA) (United Nations, 2005). Therefore, the academic institutions must actively be engaged in developing, maintaining, and sustaining a culture of disaster-resilient community at local, federal, national, and global levels.

In the globe, particularly, in South Asia, the negative impact has been driven by frequent catastrophic events creating challenges, and Nepal is not the exception of it. Nepal is one of the highly vulnerable countries in terms of disasters due to its geological formations, climatic conditions, unplanned developmental and industrial activities, limited capacities and capabilities to respond, and lack of knowledge on disaster phenomena. According to the literature, Nepal ranks in $4^{\text {th }}, 11^{\text {th }}$, and $30^{\text {th }}$ positions in terms of climatic risk index, the global risk for earthquake, and global flood risk, respectively. In addition, more than $80 \%$ of people in Nepal are directly/indirectly exposed to disaster risks (MoHA, 2019). In this context, there is a great challenge for academic institutions to produce a capable human resource that can generate knowledge through research and apply the acquired knowledge by analyzing and interpreting disaster-related events. Therefore, it is a matter of urgency to prepare the capacities in the DRRM sector to act into action in the preparedness, response, recovery and mitigation phases of the disaster cycle. The objectives of this study are to explore the existing scenarios of disaster-related academic curricula and university social responsibilities for making the disaster-resilient community in Nepal.

\section{MATERIALS AND METHODS}

The methodology mainly adopted for this study is reviewing existing literature, related policies, academic programs, and curricula. Importantly, the academic curricula of higher institutions in Nepal are widely reviewed to derive the relevant information related to the DRRM issues. In addition, the dissertations and project reports are also reviewed focusing on the DRRM scenario and the role of academia. In the review process, attention is given to the projects of bachelor, master, and doctorate degrees (Ph.D.). Meanwhile, the available resources on World Wide Web, textbooks, magazines, and other scientific publications are also reviewed intensively.

\section{RESULTS AND DISCUSSION}

\section{Disaster risk management knowledge}

This study depicts thecurrent practices and roleof academic institutions for disaster risk reduction and management (DRRM) in Nepal. It is found that the disaster research and innovation in terms of participation, cooperation, innovation, human and environment centric approaches of higher educational institutions were just at the satisfactory level in Nepal (Fig. 1). The sustainable management of disaster issues requires a higher level of knowledge, skills, and capabilities. However, the academic curricula of many higher educations are still in remembering, understanding, and recalling phases where they missed the practical applicability in terms of analysis, research and innovations. Since the 
DRRM is an interdisciplinary approach to cope with disasters, the incorporation of researchbased academic curricula is still in the infancy stage (Tuladhar et. al.., 2014).

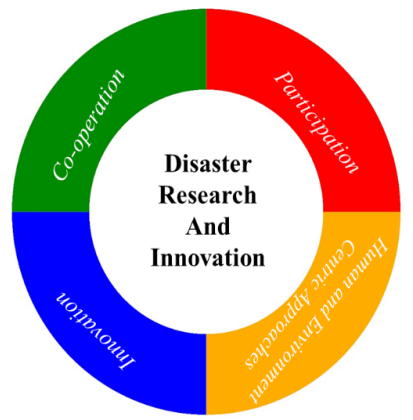

Figure 1: Characteristics of the disaster-related research and innovations

Formal education, short durational educational program, community training, and public awareness on DRRM are included in formal and informal education to some extent, however, it is mostly on the theoretical basis. After the Rio Declaration (1992), Nepal has started environmental science courses incorporating disaster issues at the university level. Sustainable developmental activities, initial environmental examinations, environmental impacts assessment, and strategic environmental assessment were incorporated into national development plans and academic curricula after 1992 in Nepal. Precisely, brief environmental studies were incorporated into the national policy level after 2019.

Indeed, environmental safety is one of the major components associated with the DRRM that are likely to be considered by all academic institutions. Environmental professionals have a key role to play in the management of disasterrelated issues because they possess valuable information about the physical, chemical, biological, and socio-economic aspects. As pioneer institutions, Tribhuvan University (TU), Pokhara University (PU), and Kathmandu
University (KU) started their Bachelor's and Master's programs in environmental science, environmental management, and environmental engineering, respectively with incorporating DRRM as the compulsory and elective subject. The balanced development, focusing on the green economy, environmentally conscious societal development, health, hygiene, adequate and safe drinking water, food and environmental sanitation, engineering activities such as construction, reconstruction, renovation, clearing, salvaging, and rehabilitation work fully or partly require serious attention of environmental sustainability and applicable in the different stages of disaster cycle (Fig. 2). Furthermore, the peculiar nature of disaster reconstruction demands the professionals to demonstrate specialized skills to contribute to DRRM and effective rebuilding. Therefore, academic institutions are required to take the responsibility of educating, training, and supporting the preparedness, response, recovery, and mitigation process by imparting sufficient disaster-related knowledge to the human and environmental safety professionals to make them more responsive to the needs and challenges of DRRM sectors.

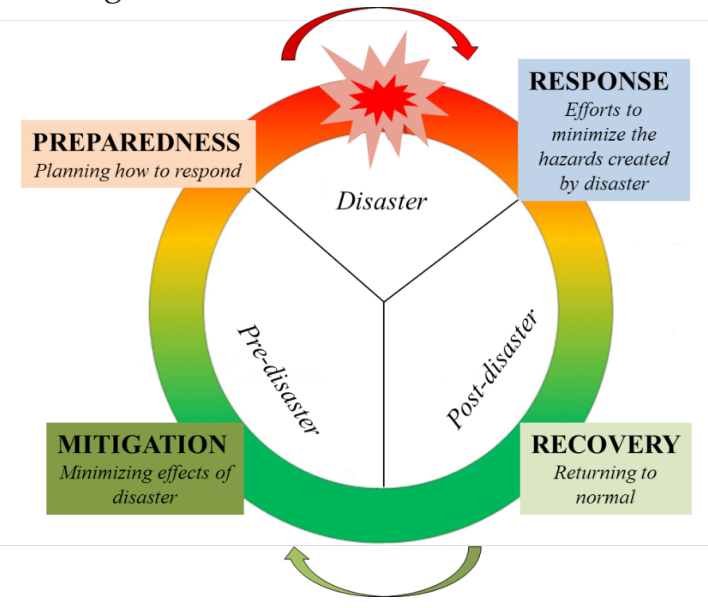

Figure 2: Schematic diagram of the disaster cycle 
Disaster education in higher academic institutions

The university plays an essential role in the DRRM process. For instance, academia has a crucial role in preparedness, response, risk reduction, and mitigation in the disaster cycle. The role of academia is not confined to the particular event of a disaster but it is applicable to support the affected community and grasp the situation from a research and innovation perspective. Academia also has significant roles in short-term, mid-term, and long-term support such as policy feedback, continuously dispatching of longer-term volunteers, and other aid. Furthermore, a university has a role in educating, developing scenarios, and providing basic level to advance level training to enthusiastic volunteers. In the case of Nepal, the reviewing literature clearly highlighted that the mainstreaming of disaster risk management is currently integrated by 10 universities (Table 1).

Table 1: Academic programs of the higher education institutions focusing on DRRM in Nepal

\begin{tabular}{|c|c|c|c|c|}
\hline S.N. & University & Level & Focus & Remarks \\
\hline 1 & Tribhuvan University & $\begin{array}{l}\text { Undergraduate } \\
\text { Graduate }\end{array}$ & $\begin{array}{l}\text { DRRM, Resilience, } \\
\text { Vulnerability, } \\
\text { Assessment, Analysis }\end{array}$ & $\begin{array}{l}\text { Focusing on Preparedness, } \\
\text { Response, Recovery \& } \\
\text { Mitigation }\end{array}$ \\
\hline 2 & Pokhara University & $\begin{array}{l}\text { Undergraduate } \\
\text { Graduate }\end{array}$ & $\begin{array}{l}\text { DRRM, Resilience, } \\
\text { Vulnerability, } \\
\text { Assessment, Analysis }\end{array}$ & $\begin{array}{l}\text { Focusing on Preparedness, } \\
\text { Response, Recovery \& } \\
\text { Mitigation }\end{array}$ \\
\hline 3 & $\begin{array}{l}\text { Kathmandu } \\
\text { University }\end{array}$ & $\begin{array}{l}\text { Undergraduate } \\
\text { Graduate }\end{array}$ & $\begin{array}{l}\text { DRRM, Resilience, } \\
\text { Vulnerability, } \\
\text { Assessment, Analysis }\end{array}$ & $\begin{array}{l}\text { Focusing on Preparedness, } \\
\text { Response, Recovery \& } \\
\text { Mitigation }\end{array}$ \\
\hline 4 & $\begin{array}{l}\text { Agriculture \& } \\
\text { Forestry University }\end{array}$ & $\begin{array}{l}\text { Undergraduate } \\
\text { Graduate }\end{array}$ & DRRM, Resilience & $\begin{array}{l}\text { Focusing on Preparedness, } \\
\text { \& Mitigation }\end{array}$ \\
\hline 5 & $\begin{array}{l}\text { Far-western } \\
\text { University }\end{array}$ & Undergraduate & DRRM, Resilience & $\begin{array}{l}\text { Focusing on Preparedness, } \\
\text { \& Mitigation }\end{array}$ \\
\hline 6 & $\begin{array}{l}\text { Lumbini Bouddha } \\
\text { University }\end{array}$ & $\begin{array}{l}\text { Undergraduate } \\
\text { Graduate }\end{array}$ & DRRI & $\begin{array}{l}\text { Focusing on Preparedness, } \\
\text { \& Mitigation }\end{array}$ \\
\hline 7 & $\begin{array}{l}\text { Mid-Western } \\
\text { University }\end{array}$ & Undergraduate & DRRM, Resilience & $\begin{array}{l}\text { Focusing on Preparedness, } \\
\text { \& Mitigation }\end{array}$ \\
\hline 8 & $\begin{array}{l}\text { Nepal Open } \\
\text { University }\end{array}$ & Graduate & DRRM, Resilience & $\begin{array}{l}\text { Focusing on Preparedness, } \\
\text { \& Mitigation }\end{array}$ \\
\hline 9 & $\begin{array}{l}\text { Nepal Sanskrit } \\
\text { University }\end{array}$ & $\begin{array}{l}\text { Undergraduate } \\
\text { Graduate }\end{array}$ & DRRM, Resilience & $\begin{array}{l}\text { Focusing on Preparedness, } \\
\text { \& Mitigation }\end{array}$ \\
\hline 10 & $\begin{array}{l}\text { Purbanchal } \\
\text { University }\end{array}$ & $\begin{array}{l}\text { Undergraduate } \\
\text { Graduate }\end{array}$ & DRRM, Resilience & $\begin{array}{l}\text { Focusing on Preparedness, } \\
\text { \& Mitigation }\end{array}$ \\
\hline
\end{tabular}




\section{i. Environmental Health in Disaster (EHD) Program}

Tribhuvan University (TU) has started disaster risk-related courses in its faculties and institutions and courses are related to climate, water, and human-induced disasters. The risk identification, analysis, interpretation, and creation of new knowledge for the DRRM is the core part of these curricula. In this context, the Institute of Science and Technology, Faculties of Humanities, Institute of Engineering are the main stakeholders for implementing these DRRM related courses under the TU. The realization of the university for incorporating such a program in academia resulted in the new introduction of the Master of Science in Environmental Health in Disaster (EHD) program. It has been started in 2019, which is a formal academic program conducted by the Central Department of Environmental Science, Institute of Science and Technology, TU. It aims to address current and emerging issues in public health and environmental safety associated with the disasters. Furthermore, it also aims to increase societal resilience to disasters.

\section{ii. Master in Disaster Risk Management}

Another good initiative is taken by the Institute of Engineering, TU. Several new courses have been adopted by the institute including climate change, water resources management, and natural disaster management at both undergraduate and graduate levels. The courses aim to enhance the capability of engineers for the management and mitigation of disaster risks by imparting multi-disciplinary knowledge. These courses are anticipated to manage disaster risks by producing capable technical human resources in DRRM sectors.

iii. Master in Crisis Management Studies Institute of Crisis Management Studies (ICMS) is a private institution affiliated with TU that focuses on the academic courses considering the management of crises resulting from both natural and man-made hazards. It advocates for a holistic approach in understanding how effectively take the measures to manage, resolve, adapt and mitigate the crisis related to disasters in the context of Nepal. The ICMS also offers training, simulation exercises, field visits, not only as part of the curriculum but as practical exercises for a range of different governmental and non-governmental organizations and initiatives.

\section{iv. Public Health and DisasterEngineering (M Sc. PHDE)}

The M Sc. PHDE program has started in 2019 at theSchool of Engineering, PU.This program aims to address current as well as future emerging issues in public health and environmental safety associated with the disaster. It also aims to increase societal resilience to disasters. The main objectives of this initiative are to develop an innovative professional graduate and doctorate human resource with sound professional and academic knowledge in public health safety through an engineering approach.

\section{Research and Academic Activities}

There is a huge gap between the available budget and activities to be performed for the DRRM. Qualified human resources are another fundamental demand in the field of disaster research and DRRM sectors. Besides, there is a lack of training courses for the community people to increase their resiliency towards disasters. Government officials are only given some opportunity for training largely on an Adhoc basis regardless of requirements. Therefore, cooperation and collaboration of academia, private businesses companies/industries with the governments, and other stakeholders are fundamental to build resilient communities. It has been in practice that the periodic plans 
which mainstream the DRR plan of provincial and local governments have been prepared by consultants which are hardly implemented due to gaps mentioned above. Therefore, the practice of preparing an integrated DRR plan based on consultations with local communities, local authorities, private sector, academia, and development agencies is whether effective or not should be utmost need of research for effective sustainable development.

\section{Role of organizations in DRRM}

DRRM is a complex process involving international, national, and local organizations along with their distinct role to play in responding to disaster situations. The key national organizations working in the field of DRRM at the federal level are illustrated in Fig. 3. At present, the Ministry of Home Affairs (MoHA) Nepal which is also the National Focal Point of Disaster Management, has been taking initiatives to address the issues of disasters and mitigate the adverse effect from them. The MoHA has a great role in all the stages of DRRM that has been working in all the 7 provinces, 77 districts, and 753 local governments. The Nepal Police, Nepal Armed Police Force, and Chief District Officers have special administrative rights to work in DRRM sectors under the MoHA. The ministry of defense also has a key role in DRRM, especially in emergency response. Similarly, Disaster Preparedness NetworkNepal (DPNet-Nepal) is a national umbrella organization of national and international agencies, established in 1996 with the objective of coordination, collaboration, learning, and sharing of the experiences. Different organizations like Asian Disaster Reduction Center (ADRC), Asian Disaster Preparedness Center (ADPC), United Nations Development Program (UNDP), International Center for Integrated Mountain Development (ICIMOD),
Practical Action, Mercy Corps, International Red Cross Society (IRCS), Cooperation for American Relief Everywhere (CARE), OXFAM, World Food Program (WFP), Save the Children Fund (SCF), Lutheran World Relief (LWR), etc. play a vital role in DRRM.

Besides, various other professional and nongovernmental organizations like Nepal Red Cross Society (NRCS), Nepal Scout (NS) are also providing highly valuable support at the time of disasters. Some organizations like Nepal Environment Society (NES), Water Induced Disaster Prevention Technical Center (DPTC), Nepal Geological Society (NGS), National Society for Earthquake Technology (NSET), and few others have contributed significantly by conducting research and training programs to raise public awareness in the country (MoHA, 2019). The transboundary collaboration for the DRRM in the river basin level is also highlighted by the platform like Koshi Disaster Risk Reduction Knowledge Hub (KDKH). It is led and driven by the members from three basin shared countries (China, Nepal, and India) to foster transboundary collaboration on disaster risk reduction and explore the interlinkages between science, policy, and practice (Shrestha and Gupta, 2019).

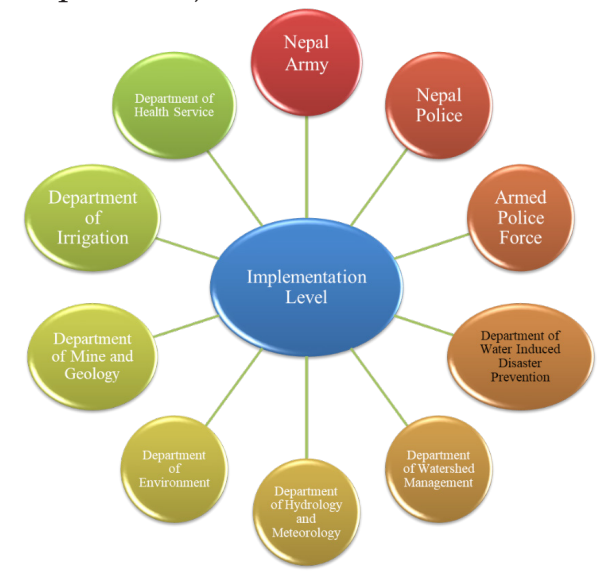

Figure 3: Organizations involving in DRRM implementation level in Nepal 


\section{Disaster risk management policy analysis in Nepal}

Nepal has been part of different international forums for the implementation of DRRM in their action plans and policy such as HygoFramework of Action (HFA 2005-2015), Sendai Framework on Disaster Risk Reduction (SFDRR) (2015-2030) (United Nations, 2015). These plans include understanding disaster risk, strengthening disaster risk governance, preparedness for effective response, and investing in disaster risk reduction for better resilience. In addition, different policies, guidelines, action plans, and strategies have been formulated and being implemented in the process of making a disaster resilience society in Nepal (Fig. 4).

In 2015, Nepal has adopted the new constitution. According to the constitution, the structure of the country shall be three levels i.e., federal, provincial, and local. Within this framework, Schedule 7, Schedule 8, and Schedule 9 implying the DRRM issues. According to the constitutional provisions, the DRRM issues are the sole responsibilities of the local governments along with the shared authorities of the federal and provincial governments. Precisely, Schedule 7 highlighted the natural and humaninduced disaster preparedness, rescue, relief, and rehabilitation activities in the concurrent powers of Federal and Provincial governments (Maharjan et. al.., 2019; MoHA, 2019). Schedule 8 listed disaster management as the sole responsibility of the local government whereas, Schedule 9 underlined the concurrent powers of all three tiers of governments with key roles and responsibilities. In addition, with the spirit of the Constitution, the Disaster Risk Reduction and Management Act (DRRMA), 2017 has been enacted. According to the Act, DRRM National Council, Executive Committee, and National Disaster Risk Reeducation and Management Authority (NDRRMA) are envisioned at the federal level.
Similarly, DRRM Council is envisioned at provincial and local levels as well. The federal, provincial, and local levels councils are chaired by Prime Minister, Chief Minister, and Mayor/President, respectively.

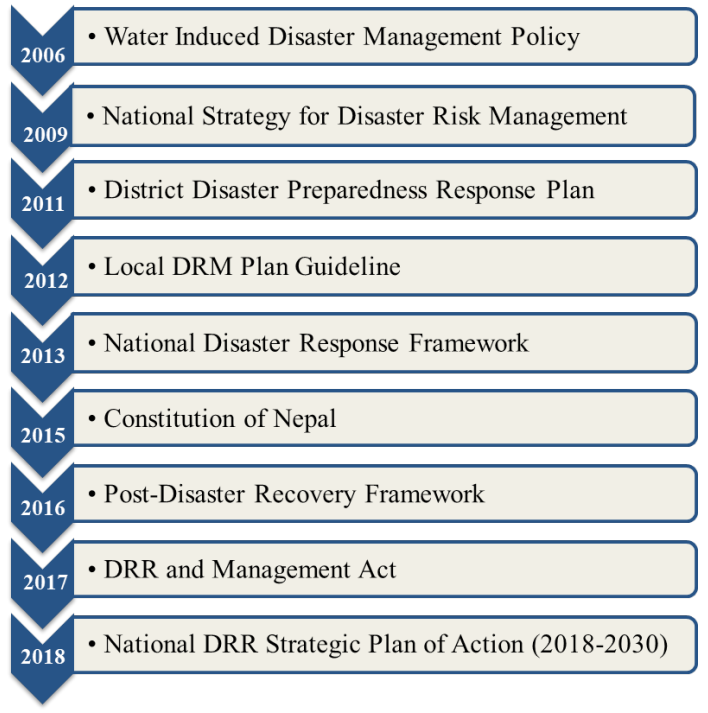

Figure 4: Key policies of Nepal related to the disaster risk management

\section{EXISTING GAPS AND WAY FORWARD}

\section{Gaps in Research and Academic activities}

The responding organizations only focus on response and recovery phases of the disasters and there is very limited research on DRRM in terms of preparedness and mitigation up to 2000. However, during the last 20 years, the academic research activities of higher education institutions have prioritized all the components of the disaster cycle. In addition to this, environment-friendly development and disaster resilience societal development is the core area of investigation for many universities in Nepal during the last two decades. Despite these positive initiatives, the systematic investigations on DRRM are still in the preliminary stage. Meanwhile, many of the research reports, dissertations, and case studies have been biased self-serving, as they have been performed not 
only by the reliable universities but also the responding agencies themselves. There is very limited work on human and environmental health safety from the perspectives of sustainability. Thus, the universities and other organizations should work together to gain synergy for the sustainable management of ever-increasing disaster risks in Nepal.

\section{Knowledge into practice}

The new knowledge and innovative research findings should be used for the betterment of society. However, a lot of innovative research comes out yearly which remains on a sheet of paper and never reaches the concerned authorities in Nepal. The concept of bringing research into use should be prioritized by both academia as well as governmental organizations. Irrespective of the limited resources, the local communities might have their disaster management approaches and practices in terms of traditional and indigenous knowledge. These knowledge systems and practices should be properly documented and integrated with the modern approaches of DRRM.

\section{Integration of science in DRRM}

The approaches for the DRRM should be focused on scientific data and real situations. However, a single disciplinary approach may not contribute sufficiently to making the disaster-resilient community at the local level. Thus, a science-based multidisciplinary approach should be adopted with minimizing the political and other interests of the people at local, provincial, and federal levels. Linking research to policy is needed to prepare for disaster beforehand. The way to link science and policy in DRRM is to hold participatory programs at the local level with engaging people. According to the constitution of Nepal 2015, both top-down and bottom-up approaches shall be adopted by different organizations involving in the DRRM sectors. For instance, the federal parliament makes the laws, acts, and regulations and provincial/local governments should follow those legal provisions in the form of the top-down approach. Whereas, the sole responsibilities of DRRM are given to the local governments and they can make their own short-term, mid-term, and long-term plans to reduce the risks and give feedbacks to the provincial and federal governments considering as the bottom-up approach. However, due to the bureaucratic nature of higher academic institutions, the incorporation of new approaches within academic programs as per the need of the country is not easy and straightforward in Nepal.

\section{Way forward}

The higher academic institutions have a great role to make the disaster resilience community by producing technical human resources and disseminating the new knowledge on DRRM sectors. The universities in particular have the great opportunity to reach out to society and contribute with educating learners, training services, creation of knowledge, and transfer to the communities. Due to high susceptibility to natural hazards, and particularly to climatic and geological events, Nepal ranks in $4^{\text {th }}, 11^{\text {th }}$, and $30^{\text {th }}$ positions in terms of climatic risk index, the global risk for earthquake, and global flood risk, respectively. In this context, the role of academia in mainstreaming DRRM is very much crucial which is also highlighted by the Constitution of Nepal 2015. In this connection, the higher academic institutions like the Central Department of Environmental Science, and Faculties of Science and Technology of TU and PU, respectively have recently adopted Environmental Health and Disaster Programs in their academic curricula. These initiatives could be the milestone for sustainable development 
and disaster-resilient communities. However, there are still many gaps for conveying the university knowledge to the community level. Thus, further initiatives should be taken to apply the scientific knowledge and research findings for making a disaster-resilient community.

\section{REFERENCES}

Maharjan, A., Khatri, S. B., Thapa, L., Pant, R. R., Pathak, P., Bhatta, Y. R., Rijal, K., and Bishwakarma, K. (2019). Solid Waste Management: Challanges and Practices in the Nepalese Context. Himalayan Biodiveristy.7: 6-18.

MoHA. (2019). Nepal Disaster Report 2019. Ministry of Home Affairs, 1-54.

Shrestha, K., and Gupta, N. (2019). A Knowledge Hub to Address Transboundary Disaster Risk and Water Security Issues in the Koshi River Basin. An ENVIS Newsletter.

Tuladhar, G., Yatabe, R., Dahal, R. K., and Bhandary, N. P. (2014). Knowledge of disaster risk reduction among school students in Nepal. Geomatics, Natural Hazards and Risk, 5(3): 190-207. https:/ / doi. org/10.1080/19475705.2013.809556

Tuladhar, G., Yatabe, R., Dahal, R. K., and Bhandary, N. P. (2015). Disaster risk reduction knowledge of local people in Nepal. Geoenvironmental Disasters, 2(1). https:/ / doi.org/10.1186/s40677-014-0011-4 United Nations. (2005). International Strategy for Disaster Reduction Hyogo Framework for Action 2005-2015: Building the Resilience of Nations. World Conference on Disaster Reduction, 25.

United Nations. (2015). Sendai Framework for Disaster Risk Reduction 2015-2030. 1-37.

www.tu.edu.np

www.nsu.edu.np

www.ku.edu.np

www.pu.edu.np

www.purbuniv.edu.np

www.lbu.edu.np

www.afu.edu.np

www.mwu.edu.np

www.fwu.edu.np

www.nou.edu.np

www.cdes.edu.np 